\title{
A GENETICAL STUDY OF DDT RESISTANCE IN THE MOSQUITO AEDES AEGYPTI
}

\author{
J. P. MARGHAM* and R. J. WOOD \\ Department of Zoology, University of Manchester
}

Received 8.iv.74

\begin{abstract}
SUMMARY
Crosses have been carried out to determine the relationship between adult DDT resistance and the three linkage groups of the mosquito Aedes aegypti.

Two linkage groups were implicated in the control of DDT resistance. In the Bangkok-HR strain resistance derived mainly from linkage group III, probably with the maor effect from the gene $R^{D D T 2}$. When resistance was transferred into a susceptible background, by outcrossing Bangkok-HR to strain 64 and reselecting, resistance in the resulting Bangkok-MR strain came from both linkage groups II and III.
\end{abstract}

\section{INTRODUGTION}

A NUMBER of studies, principally on larvae, have indicated that DDT resistance in Aedes aegypti (L) is controlled at a single locus, present in resistant strains from America, Africa and Asia (Khan and Brown, 1961; Brown and Abedi, 1962; Klassen and Brown, 1964; Inwang, Khan and Brown, 1967; Lockhart, Klassen and Brown, 1970). A major DDT resistance locus has been identified on linkage group II, although estimates for recombination between it and marker genes have varied considerably (Lockhart et al., 1970).

Other work has suggested that DDT resistance may not have such a simple genetic basis. In a strain selected with a 1:1 mixture of DDT and WARF anti-resistant compound, Pillai and Brown (1965) found DDT resistance in adults to be derived from both linkage groups II and III. A study by Wood (1967) revealed a difference in control of larval and adult resistance; a larval DDT-resistance gene $\left(R^{\mathrm{DDT} 1}\right)$ was located on linkage group II, while adult resistance was found to be controlled by a gene on group III $\left(R^{\text {DDT2 }}\right)$. Later, Wood (1970) located a modifier of larval resistance $(y)$, also on group II.

The present study set out to investigate further the linkage relationships of DDT resistance in adults of $A$. aegypti, the aim being to determine what the effect might be of a change in genetic background.

\section{MATERIALS AND METHODS}

The recessive markers used in the crosses were: red-eye $(r e)$, group I, scored in pupae; spot $(s)$, group II, reduction or loss of dorso-lateral abdominal spots in adults; black tarsus (blt), group III, reduction of white scales on the tarsae, especially of the posterior pair of legs.

* Present address: Biology Department, Liverpool Polytechnic, Byrom Street, Liverpool L3 3AF. 
Four laboratory strains were used:

$B a n g k o k-H R$, an unmarked DDT-resistant strain further selected in the laboratory.

$Q S$, an unmarked DDT-susceptible strain.

64, a marked DDT-susceptible strain which had been outcrossed to QS and reselected for the markers to improve viability.

Bangkok-MR, a marked DDT-resistant strain obtained from crossing Bangkok HR with 64, separating triple-marked individuals in the $F_{2}$ and selecting for DDT resistance over six generations (Margham and Wood, 1974).

Linkage relationships were established using two-point test cross data from reciprocal backcrosses of $F_{1}$ (susceptible $\times$ resistant) $\times$ susceptible. There were two types of parental cross: those in which the susceptible chromosome was marked with a recessive visible mutant (resistance in coupling with wild type), and those in which the resistant chromosome carried the marker (resistance in repulsion with wild type). When necessary, corrections for partial manifestation were made (Bailey, 1961).

Ambient conditions for rearing and testing with insecticide were $26 \pm 1^{\circ} \mathrm{C}$ and $70 \pm 5$ per cent R.H. At all stages lighting was kept constant to eliminate cyclical activity.

When 4-6 days old, adults were exposed to DDT using the WHO test kit (WHO, 1963), but with several changes from the recommended procedure:

1. Only 10 mosquitoes per exposure tube were used.

2. Only females were tested.

3. No holding period was observed after exposure to the insecticide.

These changes were believed to reduce variation between replicates and provide a more effective means of distinguishing susceptible and hybrid phenotypes than the standard WHO test.

\section{Results: DDT Resistance in BANGkok-HR}

Tests with strain 64 and the reciprocal $F_{1}$ 's from crossing with BangkokHR ( + s blt re $\times$ " $R$ " +++ ) established that good discrimination between susceptible and hybrid phenotypes could be obtained by $2 \frac{1}{2}$ hours' exposure to 2 per cent DDT. Above and below this exposure there was overlap between phenotypes.

$\begin{array}{ccc} & \begin{array}{c}\text { Percentage } \\ \text { knockdown }\end{array} & \begin{array}{c}\text { Number } \\ \text { tested }\end{array} \\ 64 & 100 & 466 \\ \mathrm{~F}_{1}(64 \times \text { Bangkok-HR }) & 0 & 184 \\ \mathrm{~F}_{\mathbf{1}}(\text { Bangkok-HR } \times 64) & 0 & 209\end{array}$

The $F_{1}$ was checked for markers (which when present were removed) and backcrossed to 64. A sample of the progeny was scored for the pupal marker red-eye. These and the rest of the progeny were reared to adults and exposed to 2 per cent DDT for $2 \frac{1}{2}$ hours, after which the living and dead were scored for markers (table 1, A). Replications and reciprocals did not differ significantly and are combined. 
DDT RESISTANGE IN MOSQUITO

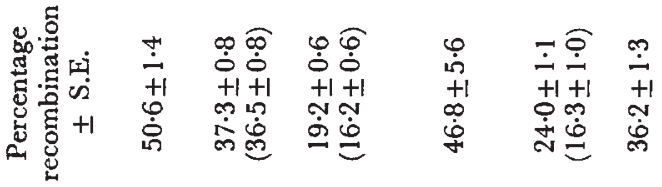

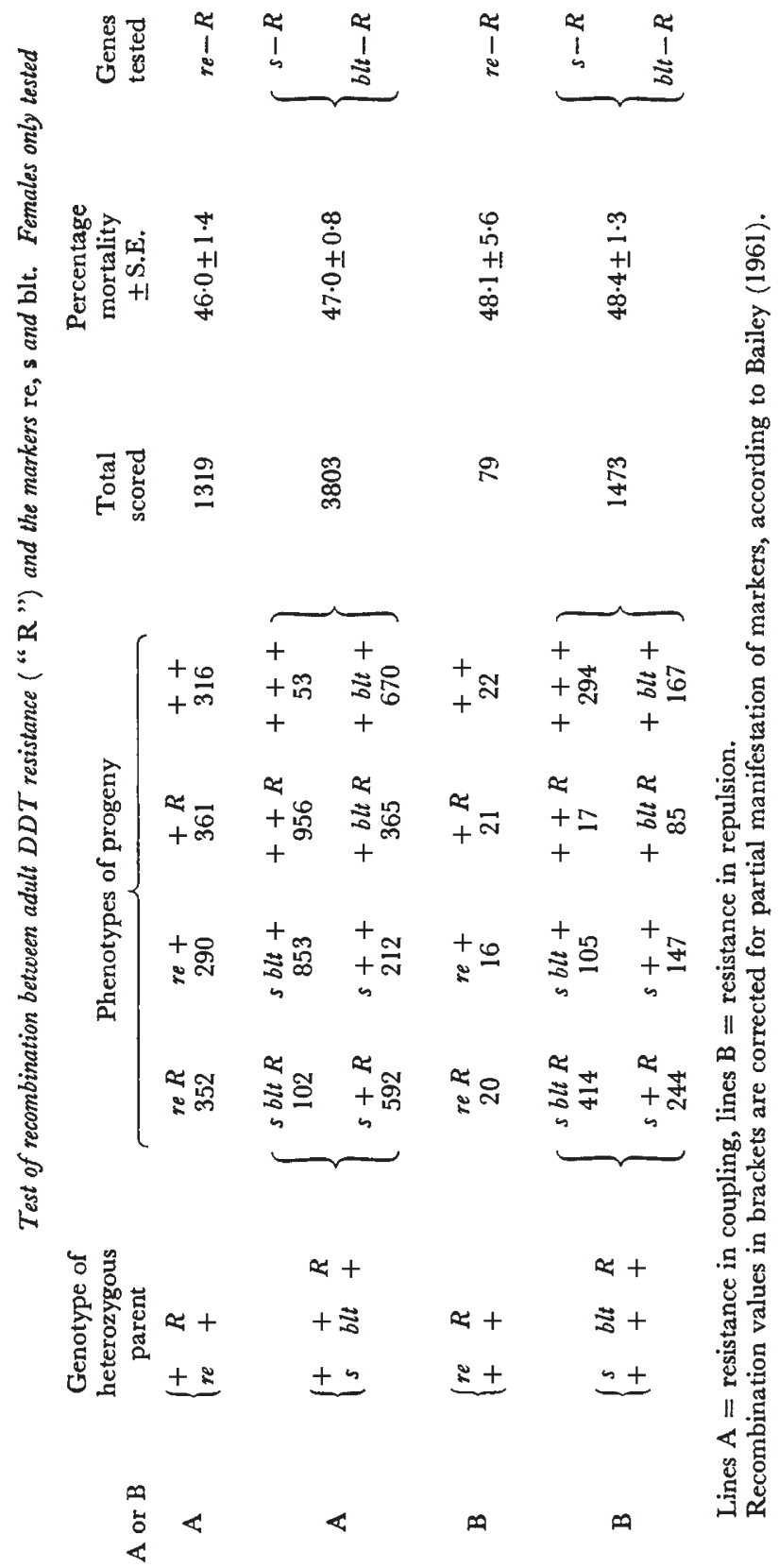


An analysis of the data (table 1, A) shows independent assortment between the gene (genes) for resistance (" $R$ ") and $r e\left(\chi^{2}=0.22, \mathrm{P}>0.50\right)$, strong linkage between " $R$ " and blt $\left(\chi^{2}=1439, \mathrm{P} \ll 0 \cdot 001\right)$, and a highly significant if loose linkage between " $R$ " and $s\left(\chi^{2}=247, \mathrm{P}<0.001\right)$.

Mortality in the backcross differed slightly, although significantly, from 50 per cent $\left(\chi^{2}=13.55, \mathrm{P}<0.001\right)$. There was a significant excess of blt phenotypes $\left(\chi^{2}=8 \cdot 2, \mathrm{P}<0.01\right)$, and a deficiency of $s$ phenotypes $\left(\chi^{2}=21 \cdot 4\right.$, $\mathrm{P}<0.001)$. The ratio of $r e: r e^{+}$was normal $\left(\chi^{2}=0.92, \mathrm{P}>0.25\right)$.

The deficiency of $b l t^{+}$is best explained as partial manifestation due to miscoring. Although the mutant phenotype is normally easy to score, mistakes can be made with insects exposed to DDT because of the loss of tarsal scales.

There is no way of knowing whether the deficiency of $s$ phenotypes was due to differential mortality or partial manifestation. The latter seems the more likely, however, since in the second series of crosses (after a change in genetic background) the $s^{+}$allele was found to be deficient (table 1, B).

Values of recombination corrected for partial manifestation of $b l t^{+}$and $s$ (as appropriate) are given in brackets in table 1, A. The estimate for recombination " $R$ "-blt is $19 \cdot 2 \pm 0.6$ per cent (uncorrected) and $16 \cdot 2 \pm 0.6$ per cent (corrected). These values are both close to the recombination value between $R^{\mathrm{DDT} 2}$ and $b l t$ of $18.2 \pm 1.6$ per cent obtained by Wood (1967), in whose crosses there was independent assortment between resistance and $s$.

The estimates for recombination " $R$ "-s is $37 \cdot 3 \pm 0.8$ per cent (uncorrected) and $36 \cdot 5 \pm 0.8$ per cent (corrected). These values are much higher than estimates based on larval studies (in which $R^{\text {DDT1 }}$ is the only major gene controlling resistance). The most recently published estimates from larval studies for recombination $R^{\mathrm{DDT} 1_{-S}}$ vary from $10 \cdot 1$ to $18.9 \mathrm{per}$ cent (Lockhart et al., 1970). Our own unpublished estimates point to a value of less than 8 per cent.

\section{Results: DDT Resistance in Bangkok-MR}

In a series of tests on strain 64 and the reciprocal $\mathrm{F}_{1}$ 's from crossing strain QS with Bangkok-MR $(++++x " R$ "s blt re), good discrimination could be obtained between susceptible and hybrid phenotypes by 2 hours' exposure to 2 per cent DDT. Above and below this exposure there was overlap between phenotypes.

$\begin{array}{ccc} & \begin{array}{c}\text { Percentage } \\ \text { knockdown }\end{array} & \begin{array}{c}\text { Number } \\ \text { tested }\end{array} \\ 64 & 100 & 193 \\ \mathrm{~F}_{1}(\mathrm{QS} \times \text { Bangkok-MR) } & 0 & 206 \\ \mathrm{~F}_{1}(\text { Bangkok-MR } \times \mathrm{QS}) & 0 & 239\end{array}$

The $F_{1}$ was checked for markers (which were removed) and backcrossed to strain 64 . The progeny of the backcrosses were exposed to 2 per cent DDT for 2 hours, after which the living and dead were scored for markers (table 1, B). (A sample had been scored for $r e$ in the pupal stage before exposure to DDT in the adults.) The reciprocals did not differ significantly and have been combined. An analysis of the data shows independent assortment between the gene (genes) for resistance (" $R$ ") and $r e\left(\chi^{2}=0 \cdot 32\right.$, 
$\mathrm{P}>0.50)$, strong linkage between " $R$ " and $s\left(\chi^{2}=397, \mathrm{P} \ll 0 \cdot 001\right)$ and a highly significant if looser linkage between " $R$ " and blt $\left(\chi^{2}=112\right.$, $\mathrm{P}<0.001$ ).

Mortality in this backcross did not differ significantly from 50 per cent $\left(\chi^{2}=1 \cdot 50, \mathrm{P}>0 \cdot 10\right)$. The ratios of $r e: r e^{+}$and $b l t: b l t^{+}$were both normal $\left(\chi^{2}=0.62, \mathrm{P}>0.25 ; \chi^{2}=3.23, \mathrm{P}>0.05\right.$ respectively), although there was a highly significant excess of $s$ over $s^{+}$phenotypes $\left(\chi^{2}=81 \cdot 7, \mathrm{P}<0 \cdot 001\right)$. This deficiency of the wild-type $\left(s^{+}\right)$phenotype is more likely to have been due to partial manifestation than to differential mortality (see previous section).

The estimate for recombination " $R$ "-s is $24 \cdot 0 \pm 1 \cdot 1$ per cent (uncorrected) and $16 \cdot 3 \pm 1.0$ per cent (corrected for partial manifestation of $s^{+}$) (table 1, B). These values are substantially higher than our own estimates for recombination $R^{\mathrm{DDT} 1}-s$ based on larval studies (see above) but comparable with values obtained by Lockhart et al. (1970). The estimate for recombination " $R$ "-blt is $36 \cdot 2 \pm 1.3$ per cent, much higher than the value for $R^{\mathrm{DDT} 2}-$ blt (see above).

\section{Discussion}

An exposure to DDT which killed all homozygous susceptibles and no hybrids (resistant $\times$ susceptible) produced close to 50 per cent mortality in two sets of backcrosses to susceptible. This observation, taken in conjunction with earlier studies (see introduction), might suggest segregation at a single resistance locus in each experiment. Yet the measured values of recombination between the gene (genes) for resistance and visible markers were quite different in the two experiments, and there was clear evidence that both linkage groups II and III were involved.

Resistance (" $R$ ") will segregate as a single gene only if the mechanism controlled by this gene has the major effect. If, for example, a second locus should influence resistance, this would cause some "susceptibles" to be resistant. The effect would be to lower mortality in the backcross below 50 per cent. It would also influence measured values of recombination between the major gene and marker genes because the penetrance of " $R^{+}$" would have been reduced; it is well known that the value of recombination between two closely linked genes, measured simply as the proportion of recombinants, will be increased artificially if the penetrance of one or both is incomplete (Bailey, 1961, pp. 74-82).

If we suppose that two genes (e.g. $R^{\mathrm{DDT} 1}$ and $\left.R^{\mathrm{DDT} 2}\right)$ contribute towards DDT resistance, one showing very low penetrance (and consequently contributing little), and the other almost fully penetrant (and making the major contribution), the measured value of linkage of the former to a given marker would be much greater than the true value whereas the measured value of linkage of the latter would be close to normal. In fact, the degree to which the values of recombination deviate from expected may be taken as an index of penetrance, in the absence of other influences upon recombination.

On the basis of this model, the two sets of crosses may be interpreted in terms of different major influences on resistance. The recombination " $R$ "-blt in the "in coupling" crosses was very similar to the value $R^{\text {DDT2}}$-blt measured by Wood (1967), suggesting that $R^{\mathrm{DDT} 2}$ contributed 
the major influence towards resistance in these crosses; while the value " $R$ "-s was abnormally high suggesting a minor effect from $R$ DDT1 due to low penetrance. In the " in repulsion" crosses, however, the position was partially reversed.

Consider first the "in coupling" crosses using Bangkok-HR. The backcross mortality in the tests was $47 \cdot 0 \pm 0 \cdot 8$ per cent, slightly but significantly less than 50 per cent. On the assumption of full penetrance for $R$ DDT2 (indicated by the recombination value with $b l t$ ), the other major gene $\left(R^{\mathrm{DDT} 1}\right)$ must show low penetrance. Otherwise mortality would have deviated further from expected. 10 per cent penetrance of $R^{\mathrm{DDT} 1}$ would account for the deviation from 50 per cent mortality observed, raising only by 1-2 per cent the apparent recombination between $R^{\mathrm{DDT} 2}$ and blt. (An example is worked out in table 2.) Low penetrance of $R^{\mathrm{DDT} 1}$ would also lead to an apparent linkage (although with high " recombination ") between resistance and $s$; this is observed.

TABle 2

The effect of 10 per cent penetrance of $\mathrm{R}^{\mathrm{DDT}}$ on the recombination between resistance $(\mathrm{R})$ and the marker blt (assuming RDDT2 is fully penetrant)

\begin{tabular}{|c|c|c|c|c|c|c|}
\hline \multirow{2}{*}{\multicolumn{2}{|c|}{$\begin{array}{l}\text { Penetrance } \\
\text { of } R D D T I\end{array}$}} & \multicolumn{4}{|c|}{ Phenotypes } & \multirow[b]{2}{*}{$\begin{array}{l}\text { Recombination } \\
R \text {-blt }(\%)\end{array}$} \\
\hline & & $R+$ & $R \quad b l t$ & $+\quad+$ & $+b l t$ & \\
\hline \multirow{2}{*}{$\begin{array}{l}\text { General } \\
\text { case }\end{array}$} & (none & $a$ & $b$ & $c$ & $d$ & $\frac{b+c}{\text { total }}$ \\
\hline & $10 \%$ & $a+0 \cdot 05 c$ & $b+0 \cdot 05 d$ & $c-0 \cdot 05 c$ & $d-0.05 d$ & $\frac{(b+0 \cdot 05 d)+(c-0.05 c)}{\text { total }}$ \\
\hline \multirow{3}{*}{ Example } & ( none & 42 & 8 & 8 & 42 & $16 \cdot 0$ \\
\hline & $10 \%$ & $42 \cdot 4$ & $10 \cdot 1$ & $7 \cdot 6$ & 39.9 & $17 \cdot 7$ \\
\hline & & \multicolumn{2}{|c|}{$\begin{array}{c}52 \cdot 5 \\
R\end{array}$} & \multicolumn{2}{|c|}{$47 \cdot 5$} & \\
\hline
\end{tabular}

It will be evident from table 2 that the ratio $++:+b l t$ is not affected by miscoring, because the classes remain proportionately the same. Using the data from these two classes only (the susceptible phenotypes), the estimated value of $R^{\mathrm{DDT}^{2}}$ blt is $15.6 \pm 0.9$ per cent (corrected for partial manifestation of $b l t^{+}$) and $14.8 \pm 0.8$ per cent (uncorrected). Neither value is significantly different from the value of $16 \cdot 2 \pm 0 \cdot 6$ per cent based on total corrected data $(t=0.56, \mathrm{P}>0.30 ; t=1.4, \mathrm{P}>0.15$ respectively). The recombination $R^{\mathrm{DDT}^{-}-b l t}$ would thus seems to be reasonably estimated at $16 \cdot 2 \pm 0 \cdot 6$ per cent (cf. Wood, 1967, 18.2 $\pm 1 \cdot 6$ units, and Hitchen and Wood, $1974,18 \cdot 8 \pm 0 \cdot 8$ units).

In the "in repulsion" crosses using Bangkok-MR there was no significant deviation from 50 per cent mortality in the tests. Yet it was evident that both linkage groups were concerned in determining resistance. It is not possible to identify the genes responsible, but it seems likely that these included $R^{\mathrm{DDT} 1}$ and $R^{\mathrm{DDT} 2}$. Indeed, a reasonable hypothesis to account for the results obtained (in terms both of mortality and levels of " recombination" with markers) is that $R^{\mathrm{DDT} 1}$ and $R^{\mathrm{DDT} 2}$ together exerted the major 
influence on resistance and that both were incompletely penetrant. But this cannot be established.

The switch in resistance mechanism seems to come about by a change in genetic background. This experiment has been repeated recently (Hitchen and Wood, 1974) with other marker strains, but without a similar effect. Thus it seems that the present finding was an exception to the general rule that adult DDT resistance in $A$. aegypti comes mainly from the gene $R$ DDT2 on linkage group III.

However, the differences in measured values of recombination between " $R$ " and visible markers observed in this study recall some of the variation found by previous authors. Coker (1966), for example, observed values of recombination between a putative gene for adult DDT resistance and $s$ of 16 and 23 units in different populations. He suggested that this might be due to an inversion. However, a difference in the relative influence of linkage groups II and III now seems an equally plausible explanation.

Acknowledgments.-Our sincere thanks go to Professor R. Dennell for providing laboratory facilities, and to Professor G. B. Craig Jr who supplied the 64 strain. J. P. M. was supported by an M.R.C. Advanced Research Studentship.

\section{REFERENCES}

BAILEy, N. J. 1961. Introduction to the Mathematical Theory of Genetic Linkage. Oxford University Press, 298 pp.

BROWN, A. W. A., AND ABEDI, z. H. 1962. Genetics of DDT-resistance in several strains of Aedes aegypti. Can. 7. Genet. Cytol., 4, 319-332.

COKER, w. z. 1966. Linkage of the DDT-resistance gene in some strains of Aedes aegypti. Ann. trop. Med. Parasit., 60, 347-356.

HITCHEN, J. M., AND WOOD, R. J. 1974. Linkage of the genes for DDT and dieldrin resistance in larvae of the mosquito Aedes aegypti L. (Unpublished.)

INWANG, E. E., KHAN, M. A. Q., AND BROWN, A. W. A. 1967. DDT-resistance in West African and Asian strains of Aedes aegypti. Bull. Wld Hlth Org., 36, 409-421.

KHAN, N. H., AND BROWN, A. W. A. 1961. Genetical studies on dieldrin-resistance in Aedes aegypti and its cross-resistance to DDT. Bull. Wld Hlth Org., 24, 519-526.

KLASSEN, W., AND BROWN, A. W. A. 1964. Genetics of insecticide-resistance and several visible mutants in Aedes aegypti. Can. J. Genet. Cytol., 6, 61-73.

LOCKHART, W. L., KLASSEN, W., AND BROWN, A. W. A. 1970. Crossover values between dieldrin-resistance and DDT-resistance and linkage-group 2 genes in Aedes aegypti. Can. 7. Genet. Cytol., 12, 407-414.

MARGHAM, J. P., AND wooD, R. J. 1974. The production of a DDT-resistant strain of Aedes aegypti marked on all three linkage groups. Can. 7. Genet. Cytol., (in press.)

PILlAI, M. K. K., AND BROWN, A. W. A. 1965. Physiological and genetical studies on resistance to DDT substitutes in Aedes aegypti. 7. econ. Ent., 58, 255-266.

wHo. 1963. Insecticide resistance and vector control: 13th report of the Expert Committee on Insecticides. Tech. Rep. Ser. Wld Hlth Org., 265, 41-56.

wooD, R. J. 1967. A comparative genetical study on DDT resistance in adults and larvae of the mosquito Aedes aegypti. Genet. Res., 10, 219-228.

wooD, R. J. 1970. The influence of the $y$ locus on DDT resistance in the mosquito Aedes aegypti. Genet. Res., 16, 37-47. 